\title{
Investigations on the surface quality of grinded inner contours using different manufacturing strategies on fused silica
}

\author{
Marcel Binder*, Sebastian Henkel", Jens Bliedtner, \\ Ernst-Abbe University of Applied Sciences Jena, Carl-Zeiss-Promenade 2, 07745 Jena, Germany
}

\begin{abstract}
In the field of optical manufacturing, fused silica has a high and constantly growing application potential. Its material advantages, such as low thermal expansion and high thermal shock resistance, as well as its high transparency from the ultraviolet to the infrared spectral range, result in a large number of application fields. For example, manufacturing processes in semiconductor technology require high-quality quartz materials throughout the wafer handling process to avoid non-permissible contamination and to withstand the high process temperatures. Another example are monolithic components for fiber preform manufacturing, where internal contours with high aspect ratios (e.g. component length to component diameter) and high surface qualities are required to draw fiber types with special properties. The demands on the complexity and accuracy of these components are constantly increasing, which is accompanied by the need to analyse and optimize modern $\mathrm{CNC}$ manufacturing techniques more and more. In the following, investigations on the grinding of internal contours with a high aspect ratio are presented, in which the influence of an ultrasonic assistance as well as different machining strategies are considered.
\end{abstract}

\section{Introduction \& Methods}

For the production of complex elements with internal contours with high aspect ratios in brittle-hard materials, the use of modern CNC technology and special tools are necessary. Numerous investigations have already demonstrated the positive properties of ultrasonic-assisted grinding. With the help of the special kinematic principle, which is based on a high-frequency longitudinal oscillation, the process forces can be reduced and thus higher material removal rates or a more gentle machining for tool and material can be achieved. [1,2] The use of ultrasonics (US) in conjunction with special hollow drills thus enables the rapid and gentle insertion of long holes in brittle-hard materials. However, the surface quality inside of the bore also plays a major role in many areas of application. Conventional polishing processes using loose grain reach their limits due to the strongly limited accessibility of the inner contours and cannot be used in many cases. One possibility for surface finishing after grinding is the so-called ultra-fine grinding using resinbonded tools. This enables average surface roughness that is already comparable with conventional pre-polishing. [3] Therefore, the diamond grains (D16) are embedded in a special resin bond, which has a certain elasticity. This can be compared with polishing pads and, due to these special tool properties, a kind of ductile grinding is presumably produced, which results in partially transparent glass surfaces with a low resulting roughness.
It is therefore generally possible to carry out pre-, fine and ultra-fine grinding of internal contours in one machine. In previous investigations on the insertion of holes of different diameters in the materials fused silica (Corning HPFS 79805F), ZERODUR $®$ and CLEARCERAM ${ }^{\circledR}$, which have already been presented in last year's abstract, it could already be shown that the surface roughness within the holes differ strongly in some cases, depending on the machining strategy used (deep drilling or helical drilling kinematics) and the measuring position (tool entry/exit). [4] In the investigations presented here, these are now examined in greater depth and extended to include the influence of ultrasonic support during pregrinding and subsequent ultra-fine grinding with different helical infeed depths and feed speeds.

\section{Examinations \& Results}

Following the mentioned investigations, the kinematic principles and grinding parameters (regarding cutting speed and feed rate) were kept constant and the influence of ultrasound on the surface roughness was analyzed on two different bore diameters $(5 \mathrm{~mm}$ and $7.5 \mathrm{~mm}$ ). In this case, all holes with a diameter of $5 \mathrm{~mm}$ are realized using a deep drilling process and the $7.5 \mathrm{~mm}$ holes are realized using helical drilling kinematics. The processed component is a fused silica cube (Corning HPFS 79805F, height $50 \mathrm{~mm}$ ), shown in Fig. 1, in which 12 through holes are drilled using a metal bonded hollow drill (tool diameter $5 \mathrm{~mm}$ / grain size D64). These include six holes with a diameter of $5 \mathrm{~mm}$ and six holes with a diameter of $7.5 \mathrm{~mm}$. For each diameter three of the bores are grinded

\footnotetext{
* Corresponding authors: Marcel.Binder@eah-jena.de, Sebastian.Henkel@eah-jena.de
} 
with the US switched on (Frequency $=27.1 \mathrm{kHz}$, Amplitude $=5 \mu \mathrm{m}$ ) and three without US. Subsequently, the roughness inside the bores is measured tactile at the tool entry and exit points and at the bore center, using the stylus method according to ISO 4288.

Using the same pre-grinding parameters, additional holes with a diameter of $7.5 \mathrm{~mm}$ and a depth of $8 \mathrm{~mm}$ are created to investigate ultra-fine grinding. For this purpose, the existing bores are reworked with a helical infeed movement of a resin-bonded grinding tool (tool diameter $5 \mathrm{~mm} /$ grain size D16). Different helical infeed depths (5 $\mu \mathrm{m}, 50 \mu \mathrm{m}$ and $150 \mu \mathrm{m})$ and feed speeds $(60 \mu \mathrm{mm} / \mathrm{min}$ and $300 \mathrm{~mm} / \mathrm{min}$ ) are selected in order to test their effect on the surface quality.

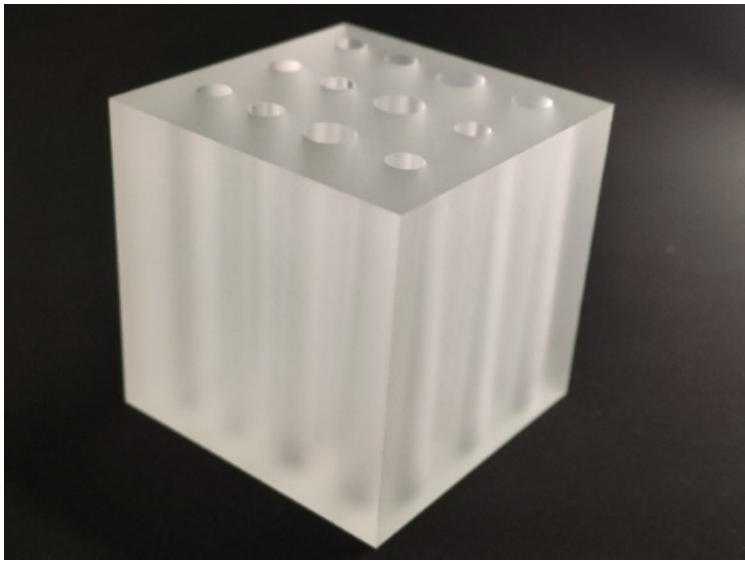

Fig. 1. component (cube $-50 \times 50 \times 50 \mathrm{~mm}^{3}$ ) with drilled holes of $50 \mathrm{~mm}$ depth

\subsection{Ultrasonic assisted grinding (drilling)}

The investigations on the holes with a depth of $50 \mathrm{~mm}$ show a tendency for ultrasonic to have a negative influence on the resulting surface roughness during deep drilling (Fig. 2) and a very low influence on the helically drilled holes (Fig. 3).

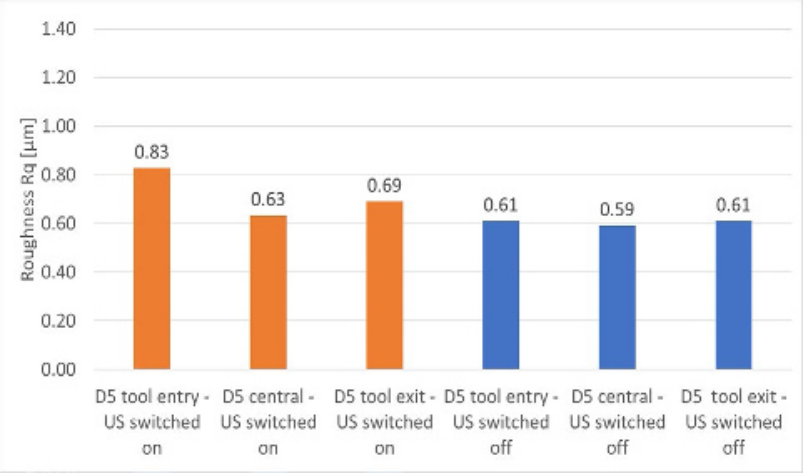

Fig. 2. Roughness results for the $5 \mathrm{~mm}$ diameter holes as a function of ultrasonics switched on / off

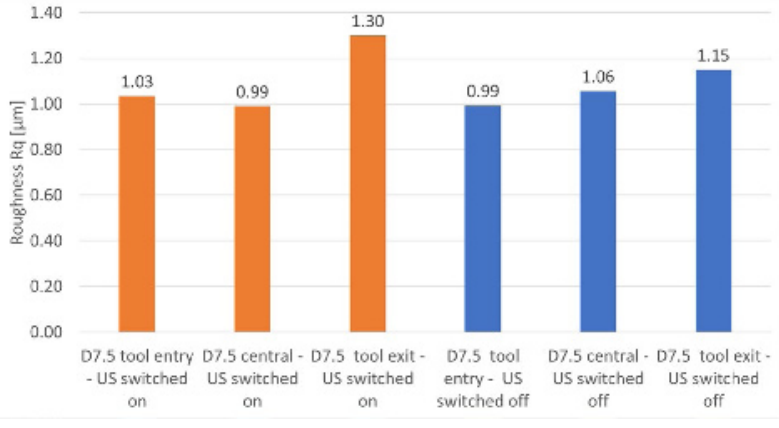

Fig. 3. Roughness results for the $7.5 \mathrm{~mm}$ diameter holes as a function of ultrasonics switched on / off

For the $5 \mathrm{~mm}$ diameter holes, average values of $\mathrm{R}_{\mathrm{q}}=0.60$ $\mu \mathrm{m}$ (without US) versus $\mathrm{R}_{\mathrm{q}}=0.72 \mu \mathrm{m}$ (with US) were determined. In contrast, the influence of ultrasound on the helically drilled holes with a diameter of $7.5 \mathrm{~mm}$ with $\mathrm{R}_{\mathrm{q}}$ $=1.07 \mu \mathrm{m}$ (without US) to $\mathrm{R}_{\mathrm{q}}=1.11 \mu \mathrm{m}$ (with US) is to be classified as very low, as already written. Furthermore, differences within the individual bore sections are discernible in both cases. The roughness values, both with and without US, at the tool entry and exit points are in some cases significantly higher than those at the center of the bore. Using the example of the $5 \mathrm{~mm}$ diameter holes, $\mathrm{R}_{\mathrm{q}}=0.82 \mu \mathrm{m}$ was determined with ultrasonic support at the tool entry, $\mathrm{R}_{\mathrm{q}}=0.70 \mu \mathrm{m}$ at the tool exit and $\mathrm{R}_{\mathrm{q}}=0.61$ $\mu \mathrm{m}$ at the bore center. It can be assumed that a different rotational stability of the long drill in the different sections is a reason for the partially strong deviations. Irrespective of the measurement location and ultrasonics, the kinematics itself show a significant influence on the surface quality, with the roughness increasing by almost a factor of 2 when the drilling kinematics are changed (deep drilling without US - $\mathrm{R}_{\mathrm{q}}=0.60 \mu \mathrm{m}$ versus helical drilling without US - $\left.\mathrm{R}_{\mathrm{q}}=1.07 \mu \mathrm{m}\right)$.

\subsection{Ultra-fine grinding}

Regarding the process of ultra-fine grinding of the internal contours with resin-bonded tools, a strong improvement of surface quality in a short time can be shown. Furthermore, it was possible to demonstrate a strong dependency of the resulting roughness on the helical infeed and feed speed. Figure 4 and 5 show a comparison of the surfaces produced as a function of the tool bond used, the helical infeed (depth of infeed) and feed speed during ultra-fine grinding. 


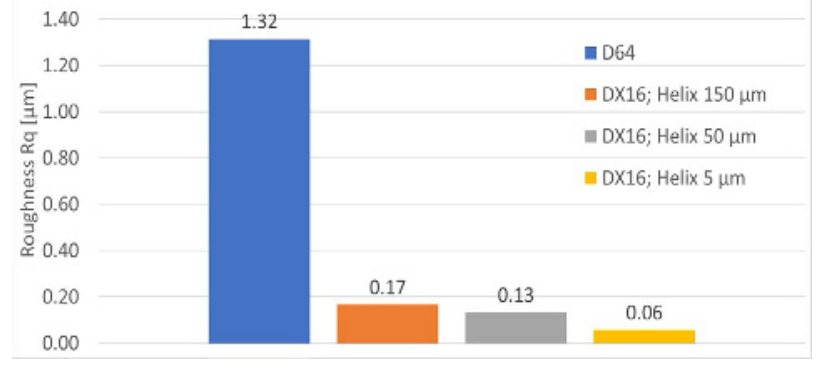

Fig. 4. Roughness results with different helical infeed depths at a feed speed of $60 \mathrm{~mm} / \mathrm{min}$

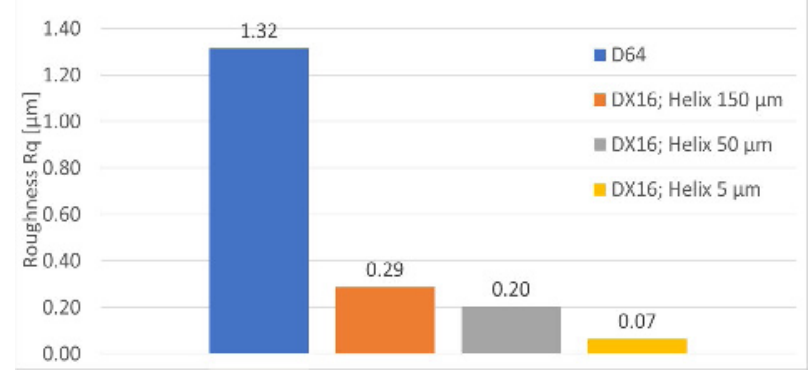

Fig. 5. Roughness results with different helical infeed depths at a feed speed of $300 \mathrm{~mm} / \mathrm{min}$

It can be seen that in both cases roughness improvements of up to about $95 \%$ can be achieved by using resin-bonded drilling tools $\left(\mathrm{D} 64-\mathrm{R}_{\mathrm{q}}=1.32 \mu \mathrm{m}\right.$ to $\mathrm{D} 16-\mathrm{R}_{\mathrm{q}}=0.06 \mu \mathrm{m}$ $\left./ \mathrm{R}_{\mathrm{q}}=0,07 \mu \mathrm{m}\right)$. Furthermore, a strong relationship between the helical infeed used and the resulting roughness can be observed. By reducing the helical infeed depth from $150 \mu \mathrm{m}$ to $5 \mu \mathrm{m}$, the roughness could be improved by about $65 \%\left(\mathrm{R}_{\mathrm{q}}=0.17 \mu \mathrm{m}\right.$ to $\left.\mathrm{R}_{\mathrm{q}}=0.06 \mu \mathrm{m}\right)$ in case of the slow feed speed of $60 \mathrm{~mm} / \mathrm{min}$. With the faster feed speed of $300 \mathrm{~mm} / \mathrm{min}$, an improvement of $76 \%$ could even be achieved $\left(R_{q}=0.29 \mu \mathrm{m}\right.$ to $\left.R_{q}=0.07 \mu \mathrm{m}\right)$. An interesting aspect is the very low resulting roughness of $0.06 \mu \mathrm{m}$ and $0.07 \mu \mathrm{m}$ for the smallest helical infeed depth, which is almost identical in both cases, despite a speed increase by a factor of 5 . The feed speed therefore has only a very small influence in the lower roughness range for the parameter ranges considered. This can be an essential factor for process duration and the associated process efficiency. Figure 6 shows (ultra-) fine grinded holes that were produced with the above parameters.

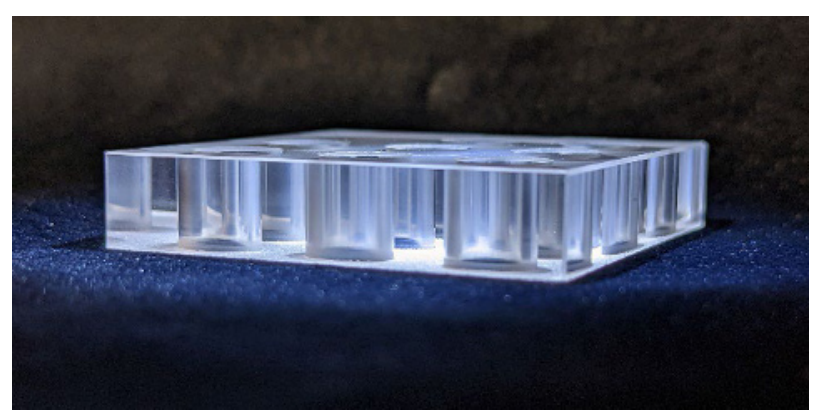

Fig. 6. Fused silica cuboid with ultra-fine grinded holes

\section{Conclusion and Outlook}

In the investigations on the insertion of long holes into a fused silica cube, it was shown that different machining strategies have a strong influence on the resulting surface qualities. When comparing the roughness achieved during pre-drilling, it was detected that a change in the machining kinematics from punctual deep drilling to helical drilling caused a deterioration of the roughness by a factor of about 2. Furthermore, negative influences of ultrasound on the process of deep drilling regarding surface roughness could be detected, whereas US had only a minor effect on the surface during helical drilling. In addition, quality differences could be found in different sections of the individual holes, which can be attributed to variable drill stability during machining. There was also evidence, that the ultrasonic assistance can improve the dimensional accuracy of the boreholes. All of this will be further investigated in future grinding and simulative analyses.

The investigations into the subsequent machining of generated holes by using ultra-fine grinding represent a promising approach for the rapid generation of internal contours with high surface quality, whereby the roughness could be improved by up to $95 \%$ through the use of resinbonded tools. The detected and only very slight influence of the feed speed in the lower roughness range represents an interesting approach for further investigations into the duration and thus economic efficiency of the grinding processes considered.

The authors gratefully acknowledge financial support by the German Federal Ministry of Economy and Energy in the funding program ZIM (funding reference: ZF4039613TV8).

\section{References}

1. M. Rost, J. Bliedtner, S. Henkel: Einflüsse des ultraschallunterstützten Schleifens auf silikatische Werkstoffe. In: Eltmann: Diamond Business 1/2016, pp. 68-77. (2016)

2. J. Zhang et al:: Study on Effect of Ultrasonic Vibration on Grinding force and Surface Quality in Ultrasonic Assisted Micro End Grinding of Silica Glass. In: Shock and Vibration, Vol. 2014, Article ID 418059 (2014)

3. S. Henkel, A.-M. Schwager, J. Bliedtner, et al.: New surface smoothing technologies for manufacturing of complex shaped glass components. In: Proceedings of SPIE Vol. 10448. (2017)

4. M. Binder, S. Henkel, A.-M. Schwager, et al.: Efficient and innovative polishing processes for smoothing complex surface geometries and internal contours on brittle-hard components. In: EPJ Web of Conferences, Vol. 238. (2020) 